\title{
"A favor de outro desenvolvimento": o Movimento Xingu Vivo para Sempre, Belo Monte e suas manifestações na World Wide Web
}

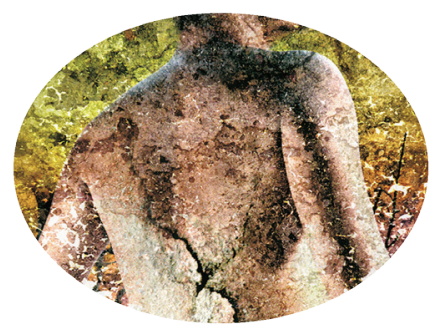

Geldes de Campos Castro*

\section{Resumo}

A Usina Hidrelétrica do Belo Monte foi projetada dentro da perspectiva da política desenvolvimentista para o Brasil na década de 1970 e ancorada na conjetura da produção energética para o país, visando responder às demandas econômicas, em particular à exploração de recursos naturais na Amazônia. As controvérsias do projeto realçaram o surgimento do Movimento Xingu Vivo para Sempre como resistência ao empreendimento. Propõe-se, neste artigo, analisar como essa visão hegemônica de desenvolvimento, materializada na hidrelétrica de Belo Monte, tem sido apreendida pelo MXVPS e como a crítica a essa visão tem suscitado a proposição de outro modelo que postula como adequado às coletividades locais. Considerando a afirmação de Castells (2006), de que os movimentos sociais têm se utilizado da internet para disseminar ideias e promover articulação, o trabalho pautou-se na análise das publicações referentes aos anos de 2010 a 2012, veiculadas no site da WEB e outros canais mantidos pelo movimento, tais como redes sociais, microblogs e sites de vídeos.

Palavras-chave: Belo Monte; desenvolvimento; internet; movimento social

\begin{abstract}
The hydroelectric plant of Belo Monte was designed from the perspective of development policy for Brasil in the 1970 and anchored in conjecture
\end{abstract}

* Mestre e doutorando em Ciências Sociais (Sociologia) pela Universidade Federal do Pará. 
energy production for the country, aiming to meet the economic demands, in particular the exploitation of natural resources in the Amazônia. Controversy Project highlighted the emergence of the Xingu Forever Alive Movement as resistance development. It is proposed in this paper to analyze how this hegemonic vision of development embodied in the Belo Monte hydroelectric dam, has been seized by MXVPS and as a critique of this view has given rise to propose another model that postulates as appropriate to the local communities. Considering the statement Castells (2006), that social movements have used the internet to spread ideas and promote joint work was based on the analysis of publications for the years 2010 to 2012, aired on the WEB site and other channels maintained by movement, such as social networks, microblogs and video sites.

Keywords: Belo Monte; development; internet; social movement

\section{Introdução}

Belo Monte tem se destacado no cenário socioambiental como um projeto polêmico e controverso. São mais de trinta anos de tentativa de implementação suscitando debates nos mais diversos círculos e envolvendo diferentes atores. Este trabalho se propõe a oferecer uma breve contribuição ao debate sobre os atores sociais que se articulam em defesa da Amazônia, aqui em particular aqueles relacionados à construção da Hidrelétrica de Belo Monte, no Estado do Pará.

A UHE Belo Monte é entendida aqui como um projeto situado na perspectiva da política desenvolvimentista para o Brasil na década de 1970 e ancorada na conjetura da produção energética para o país, visando responder às crescentes demandas econômicas, em particular à exploração de recursos naturais na Amazônia.

Pretende-se, neste artigo, compreender como essa visão hegemônica de desenvolvimento, materializada na hidrelétrica de Belo Monte, tem sido apreendida pelo MXVPS e como a crítica a essa visão tem suscitado a proposição de outro modelo que postula como adequado às coletividades locais.

Considerando a afirmação de Castells (2006), de que os movimentos 
sociais têm se utilizado da internet para disseminar ideias e promover articulação, o trabalho pautou-se na análise das publicações referentes aos anos de 2010 a 2012, veiculadas no site da WEB e outros canais mantidos pelo movimento, tais como redes sociais, microblogs e sites de vídeos. No processo de investigação privilegiou-se a metodologia qualitativa, para a realização da análise dos dados disponíveis. Nesse sentido, foram selecionadas, como objetos de análise, as publicações dos anos de 2010 a 2012, disponíveis no site da WEB e outros canais mantidos pelo movimento, em particular as redes sociais e canais de vídeos, os quais mostram como esse movimento social percebe o modelo hegemônico de desenvolvimento, assim como os elementos relacionados ao modelo que demandam como apropriado. A ferramenta de busca no site foi o veículo utilizado para a procura de postagens a fim de subsidiar a análise neste trabalho. A busca pela palavra desenvolvimento retornou um total de 338 resultados. Destes, apenas 33 foram efetivamente utilizados na análise, uma vez que forneciam os elementos necessários para o objetivo aqui proposto.

O texto a seguir se estrutura em três seções principais. A primeira pretende traçar um breve panorama da ocupação da Amazônia brasileira, a fim de entender o contexto em que é gestado o projeto de construção de Belo Monte no rio Xingu. A seguir, abre-se uma seção para tratar das resistências a Belo Monte, nesse caso com a materialização no Movimento Xingu Vivo para Sempre, enfatizando suas articulações via WEB, demonstrando como esta tem sido utilizada como veículo de desinvisibilização das questões amazônicas, particularmente no tocante aos grupos periféricos. A terceira seção procura perceber a visão que o movimento possui a respeito do padrão de desenvolvimento pensado para o Brasil, bem como os elementos apontados que demandam outro modelo de desenvolvimento que considere a existência e a reprodução dos modos de vida das populações afetadas pelo empreendimento.

\section{Ocupação da Amazônia e o projeto Belo Monte}

O projeto Belo Monte remonta os idos da década de 1970, caracterizandose por ser um projeto militar, fundado em uma lógica desenvolvimentista e inserido no contexto de integração da Amazônia brasileira (ZHOURI, 2010). Segundo Loureiro (2004), os projetos de integração da Amazônia iniciam 
antes mesmo da ditadura militar, em 1961, com a abertura da rodovia BelémBrasília. No período em que se seguiu ao golpe, porém, essa integração se amplia e permanece durante todo o período de transição. Destaca ainda, Loureiro, que a ocupação da Amazônia ocorreu com base em dois vetores: o econômico, ancorado na aliança e apoio do capital, e o geopolítico, pautado no argumento da necessidade de defesa da fronteira e ocupação do mito do vazio demográfico da região.

Essa ocupação justificou-se no argumento das "necessidades" prementes, tais como: abertura de novos mercados consumidores para os produtos industrializados provenientes do Centro-Sul do país incorporando, dessa forma, a Amazônia ao cenário do mercado nacional; expansão dos mercados de trabalho, empregando os excedentes populacionais do Nordeste; e, finalmente, de aproveitamento do potencial mineral, madeireiro e pesqueiro na Amazônia, com vistas à exportação, apontando um equilíbrio no balanço financeiro do país e visando sanar o endividamento crescente, o que se deu, principalmente, em virtude do investimento na industrialização pesada do país, da construção da nova capital do Brasil no Planalto Central e da abertura da rodovia Belém-Brasília. Importante ainda considerar os motivos designados pelo Estado como sendo de segurança nacional, tal como a necessidade de ocupação do território pelo capital, a fim de afastar a "ameaça" de que novos movimentos sociais no campo, a exemplo das Ligas Camponesas, viessem a se instalar na região sob a forma de guerrilhas rurais (LOUREIRO, 2004).

As medidas governamentais para o desenvolvimento da Amazônia incluíram a implantação de infraestrutura, materializada em um programa amplo de construção de rodovias, o que tornaria possível a ligação da região entre suas partes, bem como com a capital federal. Nessa perspectiva, foram implantados em condições adversas os seguintes projetos rodoviários: a Transamazônica, Perimetral Norte, Cuiabá-Santarém, Porto Velho-Manaus e Belém-Brasília. Já durante a abertura das estradas o contato dos índios com as frentes de trabalho resultou na morte de significativo número de membros das comunidades indígenas, ocasionadas pela transmissão de doenças, até então desconhecidas por esses povos. Ainda na linha dessas medidas, ganha destaque o desenvolvimento de um amplo programa de aproveitamento do potencial hidrelétrico da região (KOHLHEP, 1981).

$\mathrm{Na}$ década de 1970, com as crises do petróleo, o governo brasileiro 
empreendeu a construção da usina hidrelétrica de Tucuruí, visando atrair a indústria eletro intensiva de alumínio para a Amazônia. A energia dessa hidrelétrica abasteceria as fábricas da Alumar, a cidade de Belém, as fábricas da Alcoa em São Luís do Maranhão, além da Albras e Alunorte (COELHO, MIRANDA, WANDERLEY e GARCIA, 2010).

Ainda na década de 1970, foi gestada a construção da hidrelétrica de Belo Monte (Figura 1), a partir do inventário do potencial hidrelétrico do rio Xingu, elaborado pela Cenec, empresa de consultoria pertencente ao Grupo Camargo Corrêa e apresentado em 1980 pela Eletronorte (BERMANN, 2012). Na ocasião foi denominada de Kararaô, mas por conta de uma série de controvérsias, teve seu projeto de construção adiado, porém com tentativas de recuperação por diversas vezes. Sem êxito, entretanto.

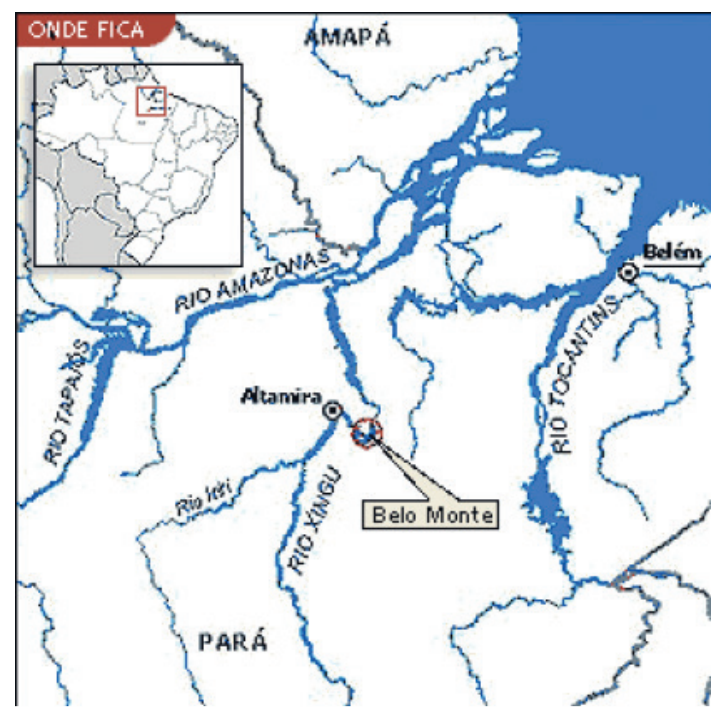

Figura 1 - Localização de Belo Monte.

Fonte: Instituto Socioambiental - ISA.

Linha de frente do Programa de Aceleração do Crescimento - PAC, do governo federal, a construção da UHE Belo Monte teve os questionamentos sobre sua viabilidade intensificados a partir de fevereiro de 2010, quando a licença prévia para a construção foi concedida pelo Ministério do Meio Ambiente. Dentre os questionamentos destaca-se o argumento de que o ser humano ocupa pouco espaço nas discussões. Segundo Ravena e Teixeira (2010), 
o Estudo de Impactos Ambientais - EIA apresenta uma série de lacunas, o que teria como objetivo obscurecer os impactos para as diversas categorias sociais existentes nas áreas que deverão ser atingidas, com isso diminuir-se-iam os custos com as transações e processos indenizatórios, ocultando impactos sobre os diversos modos de vida das populações residentes na Amazônia.

Os estudos em relação aos efeitos da execução do projeto têm apresentado resultados divergentes. Os dados provenientes dos estudos oficiais sobre os impactos não são ratificados por estudos realizados em outras instâncias, como Universidades, por exemplo. Um dos mais importantes documentos publicados foi o Painel de Especialistas, elaborado por profissionais de diversas áreas do conhecimento e vinculados a diferentes instituições de ensino e pesquisa, analisando diversos aspectos referentes aos impactos provenientes da efetivação dessa obra. No entanto, não houve nenhuma tentativa de diálogo com esses pesquisadores muitas vezes desqualificados e ridicularizados em audiências públicas (MORAL HERNÁNDEZ e MAGALHÃES, 2011; ZHOURI, 2011). Importante ressaltar que este não foi o primeiro estudo sobre tal empreendimento. Em 2005 foi publicado o livro Tenotã-mõ, organizado por Oswaldo Sevá e Glenn Switkes, o qual aponta os impactos danosos ao ambiente natural e aos diversos agrupamentos sociais ali existentes, em particular os povos indígenas.

\section{Resistência, atores e articulações em rede}

O principal ator social a compor uma frente de resistência à construção da hidrelétrica de Belo Monte é o Movimento Xingu Vivo para Sempre ou simplesmente MXVPS. É resultante de manifestações coletivas em torno da defesa do rio Xingu, na Amazônia brasileira, bem como dos modos tradicionais de vida das populações indígenas, ribeirinhas e daquelas residentes nos bairros da periferia da cidade de Altamira, principalmente, os quais serão diretamente afetados pelas consequências do barramento do rio. Em sua página da WEB, o movimento assim se define:

O Movimento Xingu Vivo para Sempre (MXVPS) é um coletivo de organizações e movimentos sociais e ambientalistas da região de Altamira e das áreas de influência do projeto da Hidrelétrica de Belo Monte, no 


\begin{abstract}
Pará, que historicamente se opuseram à sua instalação no rio Xingu. Além de contar com o apoio de organizações locais, estaduais, nacionais e internacionais, o MXVPS agrega entidades representativas de ribeirinhos, pescadores, trabalhadores e trabalhadoras rurais, indígenas, moradores de Altamira, atingidos por barragens, movimentos de mulheres e organizações religiosas e ecumênicas (http:// www.xinguvivo.org.br/quem-somos/)
\end{abstract}

Mais de uma centena de organizações se juntam na composição do movimento, que ao se definir como um coletivo de organizações e movimentos sociais e ambientalistas traz para si as duas preocupações: a social e a ambiental. Tais preocupações são manifestas nessa composição do movimento, agregadas pelas diferentes matrizes representativas que se juntam para corporificar as ações.

Por ocasião do I Encontro dos Povos Indígenas do Xingu, no final da década de 1980, na cidade de Altamira, as controvérsias em torno do projeto ganham notoriedade. Os responsáveis pelo empreendimento tomam a decisão de mudança de nome da usina hidrelétrica de Kararaô para Belo Monte, em face dos protestos dos grupos indígenas locais (COELHO, MIRANDA, WANDERLEY e GARCIA, 2010). Entretanto, os estudos de aproveitamento do potencial hidrelétrico da região não param, estendendo-se pelas décadas seguintes.

O Encontro Xingu Vivo paraSempre, realizado 19 anos após o I Encontro dos Povos Indígenas do Xingu, reuniu representantes de movimentos sociais, populações indígenas, ribeirinhos, experts e organizações da sociedade civil, com a finalidade de implementar debate sobre os impactos de Belo Monte, apresentando como documento final a Carta Xingu Vivo para Sempre, na qual há, entre outros aspectos, o questionamento do modelo de desenvolvimento atual, sobre o qual se assenta o empreendimento. Essa carta foi referendada por mais de cem signatários, sendo que mais da metade é composta por representantes de nações indígenas, das quais 26 compreendem grupos da etnia Kaiapó.

Percebe-se uma ampla rede de relações estabelecidas entre diversos atores, utilizando a World Wide Web e seus recursos de interação como amplificadora do movimento e de suas demandas. Segundo Castells (2008), a lógica das redes é uma das características do paradigma tecnológico as quais se 
adaptam à complexidade crescente da interação e aos modelos imprevisíveis de desenvolvimento derivados do poder criativo dessa interação. Nessa lógica, as organizações locais deixam de ocupar papel de coadjuvantes para assumirem a posição de protagonistas, modificando o sentido do olhar, para o qual a Amazônia é mostrada "de dentro para fora" e não mais ao contrário, como nas décadas anteriores na presença de personalidades de projeção internacional se fazia necessária para dar visibilidade às demandas da região. A investigação na WWW mostrou os seguintes veículos mantidos pelo movimento (Quadro 1).

Quadro 1 - Sites e endereços da WEB

\begin{tabular}{|l|l|}
\hline Site Oficial & http://www.xinguvivo.org.br/ \\
\hline Facebook & $\begin{array}{l}\text { https://www.facebook.com/groups/130833970297954/ } \\
\text { https://www.facebook.com/movxinguvivo }\end{array}$ \\
\hline Orkut & $\begin{array}{l}\text { http://www.orkut.com.br/Main\#Profile?u } \\
\text { id=2540907695900017321 }\end{array}$ \\
\hline Twitter & https://twitter.com/xinguvivo \\
\hline YouTube & http://www.youtube.com/user/campanhaxinguvivo \\
\hline Flickr & http://www.flickr.com/photos/xinguvivo/ \\
\hline
\end{tabular}

Fonte: World Wide Web.

A página oficial do movimento (http://www.xinguvivo.org.br/) apresenta layout semelhante aos disponibilizados pelos principais bloggers, com uma coluna principal com maior disponibilização espacial e outra lateral de largura mais reduzida. No cabeçalho do site, em caracteres pequenos, destacam-se as seguintes seções: Ação, Notícias, Documentos, Deu na Imprensa, Compartilhe, Quem somos e Contato, correspondendo ao "mapa do site".

Pouco abaixo do cabeçalho, com bastante destaque, ocupando toda a largura da coluna principal, observa-se uma série de slides de transição alternada, com fotos impactantes, chamando a atenção para algumas notícias, as quais possuem hiperligações para as notas ali veiculadas, redirecionando o internauta para aquelas de seu interesse. A coluna principal dá destaque para dois aspectos: notícias e imagens. Em relação às notícias, essas estão divididas em duas seções 
denominadas "Últimas Novidades" e "Deu na Imprensa". A primeira referese àquelas notícias veiculadas no próprio site, servindo como divulgadora das ações do movimento, bem como a releitura dos acontecimentos relacionados à causa. Há um segundo destaque para notícias veiculadas na imprensa, as quais são replicações dos principais veículos de comunicação, em geral, como esperado, aquelas que apontam aspectos negativos relacionados à construção de Belo Monte. As informações veiculadas por atores externos, aqueles sem envolvimento direto com a questão, de certa forma, são aproveitadas para legitimar e confirmar as posições do movimento. Significa que outros atores percebem e ratificam aquilo que o movimento vem denunciando.

Destaca-se na parte superior direita um espaço para buscas, tanto internas quanto externas, permitindo aos visitantes do site localizar as informações desejadas de forma mais rápida, ou mesmo buscando em outros locais da WEB informações relacionadas àquilo que lhe interessam. A presença nas diferentes redes sociais, tais como Facebook, Twitter, Flickr, Orkut e YouTube demonstra o caráter de interatividade do site e a tentativa de alcançar o maior número possível de adesão. Há ainda um campo para "newsletter", que é o ambiente disponível àqueles que desejam receber informações veiculadas no site. Após inscrição são encaminhadas informações para o e-mail do interessado sempre que a página sofrer alguma atualização ou sempre que novos eventos forem realizados, reforçando o aspecto da interatividade.

Os diversos canais utilizados não apresentam informações significativas sobre a constituição do movimento. Apenas no perfil do Orkut há uma descrição inicial com nomes de lideranças e telefones para contatos, o que constitui um diferencial, pois nas outras estruturas pesquisadas há pouca informação sobre os atores que compõem a organização. Para perceber quem são os envolvidos, é necessário montar uma espécie de mosaico com informações entrecortadas de diversas partes das páginas pesquisadas, como manifestos, cartas e similares. Talvez essa quase ausência de informações devase ao fato de os atos proibitivos da justiça em relação ao contato das lideranças com o empreendimento e do tensionamento gerado em torno desses líderes. Da mesma forma, não é encontrada muita informação sobre os parceiros do movimento. Foi possível perceber a existência de algumas articulações em rede como na autoria do vídeo "Defendendo os rios da Amazônia", feito em parceria com a Amazon Watch e International Rivers, organizações não 
governamentais com sede nos EUA, que se propõem à defesa dos rios e dos povos que nele pautam suas relações e sobrevivência. Essa articulação só foi possível ser percebida por meio das hiperligações que direcionam ao site de vídeos YouTube, onde o movimento mantém um canal com vários outros vídeos.

Um aspecto importante a ser observado a respeito do MXVPS diz respeito à amplitude que a causa assumiu. A plasticidade da internet foi utilizada sobremaneira a esse respeito. As ações e manifestações em nome do movimento demonstram isso. Nota-se a proliferação de manifestações em diferentes canais da WEB, fazendo defesa do nome/marca MXVPS. Na rede social Facebook consta um número significativo de páginas e perfis associando, de diferentes formas, alguma relação com o movimento.

Ações são disparadas em diferentes regiões do país remetendo de alguma maneira ao MXVPS. Essas iniciativas são replicadas na internet em perfis pessoais das redes, que convocam ao atendimento de momentos presenciais, em geral manifestações, debates e outros eventos, cujos registros são posteriormente, ou ao mesmo tempo postados na rede social, correspondendo a um padrão que se repete: convite - replicação - ação - registro - replicação. $\mathrm{O}$ virtual corresponde aqui ao elemento fundante que dissolve a dimensão espaço-temporal. Os padrões são novamente repetidos por meio de replicações em perfis pessoais, que são marcados pelas interações aleatórias e espontâneas, sendo alçadas à categoria de "novas" sempre que alguma ação interativa ali é realizada.

Da mesma forma, em outros recursos da internet, tais como o canal de vídeos do YouTube e microblog Twitter, as ações são repetidas sempre que novos acessos são feitos, relembrados e renovados a cada comentário, postagem, ou interação, voltando sempre ao status de "novo". Como exemplo disso há o caso da hashtag \#PareBeloMonte ter sido mencionada mais de dez mil vezes, fato esse também ter sido alvo de comentário no site do movimento.

Nessas articulações em rede destaca-se também o Comitê Metropolitano do Movimento Xingu Vivo para Sempre que se propõe trazer o debate sobre a situação no Xingu para a região metropolitana. Criado em 2009, o comitê passou a ter intensa presença na WEB. O blog criado pelo comitê aponta dois objetivos para sua atuação: informar sobre os reais interesses subjacentes à construção da hidrelétrica e mostrar o posicionamento dos 
povos indígenas, alertando para as consequências da construção. Torna-se assim mais um canal de divulgação disponível para a contestação sobre a materialização da hidrelétrica de Belo Monte, procurando dar visibilidade para as populações ali residentes, privilegiando a presença dos povos indígenas. Apresenta possibilidades de interação após cada postagem, com ícones para compartilhamento nas principais redes sociais, assim como disponibiliza espaço aberto para comentários sobre os materiais postados.

O blog do Comitê Metropolitano atua como um importante recurso para divulgação de ações realizadas, tanto aquelas ocorridas na capital como outros eventos realizados em outros níveis. Chama para momentos presenciais, abre espaço para o debate das questões postas, procurando cumprir, dessa forma, os objetivos a que se propõe.

O importante disso é perceber que não se trata apenas de informações sendo replicadas na grande rede, mas sim a composição de espaços abertos de debates, nos quais se pensa a importância e a participação da sociedade civil nas decisões, principalmente naquelas que provocam modificações nas configurações sociais, como é o caso da polêmica em torno da construção da usina de Belo Monte. Mais ainda: trata-se de espaço de construção e exposição de proposições e alternativas.

\section{A favor de outro desenvolvimento}

O movimento questiona as propostas de desenvolvimento pensadas para a região, denunciando a maneira como são articuladas e implementadas, procurando demonstrar que as populações locais não são beneficiadas; ao contrário, sofrem os efeitos danosos desses projetos, ao mesmo tempo em que procura tecer pistas para se pensar outro tipo de desenvolvimento para a região.

Uma questão aqui a ser destacada é sobre "quem fala pelo movimento" ou "quem o movimento permite falar em seu nome". E ainda, o que é "dito pelo movimento e seus porta-vozes". A lógica de que em certas circunstâncias determinadas opiniões não refletem, necessariamente, a visão do veículo, no caso do Xingu Vivo não se aplica. As reportagem e postagens (posts) escolhidas para serem replicadas no site são apenas as que estão de acordo com seu ponto de vista, dessa forma as vozes que se manifestam e que são replicadas no 
site estão de certa forma falando pelo movimento. Seguindo esse raciocínio, se estiverem postadas nos canais da WEB mantidos pelo Xingu Vivo, são consideradas aqui como ditas movimento. Alguns atores ganharam projeção, tais como dom Erwin Kräutler, bispo do Xingu, e o procurador da República, Felício Pontes. São estes que inúmeras vezes falam em prol das populações, assumindo um papel de defensores da região e dos grupos sociais que ali residem.

Nas postagens analisadas uma imagem recorrente é a do desenvolvimento predatório. O modelo imposto para a região desconsidera as populações, até mesmo porque se encontram em uma situação de invisibilidade. Segundo Felício Pontes, em entrevista publicada em 6 de setembro de 2011 pela revista Época e replicada no site, intitulada "Um procurador contra Belo Monte", essa situação dificulta qualquer tentativa de ajuda, uma vez que é muito difícil tentar defender os interesses de quem é invisível. Há, portanto, a necessidade de desinvisibilizar esses povos, nesse sentido, seria coerente afirmar que o uso que tem sido feito da internet pelo MXVPS tem de certa forma servido para expor a existência dessas populações, ratificando que não se pode mais conceber o mito do vazio demográfico na região amazônica.

O estado de invisibilidade, entretanto, seria uma estratégia utilizada pela "burocracia de Brasília", segundo Pontes. Os povos da floresta são um entrave ao desenvolvimento, uma vez que seu padrão de vida não coaduna com as perspectivas pensadas para o país. Não estando de acordo, a alternativa é não considerá-los em sua existência. Esses modos de vida contrastam na forma de se relacionar com o ambiente, diferindo daquilo que se chama de desenvolvimento predatório, nas palavras do próprio procurador: "O desenvolvimento predatório se opõe à preservação ambiental. Não enxerga o meio ambiente como o lar, a casa, o habitat de todos os seres vivos. Mas sim como recurso econômico a ser exaurido para gerar lucro”. Abramovay (2010) aponta que essa prática é habitual para a maioria do empresariado e não apenas de grupos marginais. É a maneira dominante de fazer negócios e, segundo essa visão, promover o desenvolvimento regional. É uma prática comum observada em relação à Amazônia nas mais diversas atividades e modalidades tradicionais de uso dos recursos, como a pecuária extensiva e a extração de madeira ilegal, por exemplo. Qualquer tentativa que vise coibir isso é vista como entrave ao desenvolvimento. 
A ideia do desenvolvimento predatório é presente em grande parte das publicações analisadas e a hidrelétrica de Belo Monte é enfatizada como exemplo desse tipo de desenvolvimento. Considera-a como um falso projeto de desenvolvimento nos moldes dos anteriores, uma vez que não originaram benefícios para os povos da floresta ou quando trouxeram foi o mínimo que se poderia esperar. Para demonstrar isso, destaca a fala de um morador do município de Pacajá ao reivindicar energia elétrica para sua comunidade: "Meu município fica a $150 \mathrm{~km}$ da usina de Tucuruí e até hoje não chegou energia elétrica lá. Se construírem Belo Monte estaremos a 140 km de mais uma usina. Vamos continuar sem energia".

Para Abramovay (2010), a utilização dos recursos na Amazônia segue um estilo que sempre se repete: o de conceber os projetos e, apenas posteriormente, algumas medidas para atenuar os impactos ambientais são elaboradas. Em outras palavras, essa é uma estratégia de crescimento econômico em que o meio ambiente é visto como uma mera externalidade.

Dom Erwin Kräutler, em entrevista publicada em 6 de junho de 2012, intitulada "Dom Erwin Kräutler: 'Hoje vivemos em uma ditadura civil' parte 5", afirma que o desenvolvimento, sob a ótica do governo, em particular do ex-presidente Lula, significa apenas o aumento do PIB, desconsiderando os impactos sociais e ambientais. Afirma que as concepções de desenvolvimento da época da ditadura e a do governo atual são semelhantes. A diferença estaria apenas no fato de considerar que a ditadura hoje é civil, eleita. Justifica isso afirmando que os direitos dos indígenas assegurados na Constituição Federal não foram garantidos, principalmente no que se refere à consulta às populações, o que é previsto no artigo 321, parágrafo 3. ${ }^{\circ}$ :

O aproveitamento dos recursos hídricos, incluídos os potenciais energéticos, a pesquisa e a lavra das riquezas minerais em terras indígenas só podem ser efetivados com autorização do Congresso Nacional, ouvidas as comunidades afetadas, ficando-lhes assegurada participação nos resultados da lavra, na forma da lei.

As cartas e documentos oficiais emitidos pelo movimento apresentam critérios pautados nessas experiências alternativas ao padrão desenvolvimentista hegemônico, o que leva o movimento a se posicionar de forma explícita a 
favor de outro modelo para a região pautado na implementação eficaz de políticas públicas nas áreas de saúde, educação, transporte e segurança; na demarcação e proteção de novas territorialidades; no incentivo do extrativismo e da agricultura familiar em bases agroecológicas; na proteção do corredor de sociobiodiversidade do território Xingu, o que significa, em última instância, o não barramento dos rios da região.

Escobar (2000) afirma que é necessário descolonizar os imaginários a fim de conceber uma realidade alternativa, fixando as atenções nas margens do sistema, nas práticas locais, nas culturas substantivas realmente existentes e invisibilizadas pelo metadiscurso desenvolvimentista. A Carta Xingu Vivo para Sempre apresenta uma série de proposições do que denomina de um novo tipo de desenvolvimento, na perspectiva da ampliação de experiências alternativas à modernização e ao desenvolvimento. São experiências que tomam como referentes as vivências das populações e os modos que estas encontram para fazer frente às imposições dos padrões hoje predominantes. As reivindicações dessa carta, doze no total, são tratadas como componentes de um projeto de desenvolvimento, o qual corresponde aos interesses dos moradores daquela região. Esse projeto leva em consideração aspectos no âmbito da governança, postula a desinvisibilização social das populações tradicionais, volta-se para a proteção das florestas, a agroecologia e a implantação de políticas públicas eficazes, principalmente nas áreas de saúde e educação.

Em outra carta, dessa vez dirigida à presidente Dilma Rousseffe endossada por mais de oitenta entidades, dentre as quais constam organizações locais, bem como organizações transnacionais, a questão do desenvolvimento ganha tônica novamente. O movimento denuncia os procedimentos referentes ao projeto, enfatizando que propostas inovadoras foram abandonadas em face do projeto desenvolvimentista das obras do PAC. Apresenta em suas proposições, também em número de doze, a criação de debates para o planejamento energético do Brasil, envolvendo a sociedade, movimentos sociais, ONGs e a comunidade acadêmica, segmentos hoje ausentes das decisões, uma vez que esses grupos não dispõem de recursos de poder para imprimir suas demandas e especificidades na agenda que define a matriz energética do país (RAVENA e TEIXEIRA, 2010).

Em um trecho particularmente esclarecedor, enfatiza que foram perdidas oportunidades para aquilo que considera promoção de um "outro 
desenvolvimento possível na Amazônia do século 21, partindo dos anseios das populações locais e pautado em princípios de justiça social, sustentabilidade ambiental e inovação econômica, com valorização da biodiversidade e dos serviços ambientais" (Carta à presidente Dilma Rousseff). As proposições apresentadas acima podem ser ligadas às palavras de Felício Pontes ao afirmar, na entrevista anteriormente referida, que é preciso tecer outro tipo de racionalidade que considere as questões ambientais e as necessidades das coletividades envolvidas. As proposições aqui sintetizadas se aproximam daquilo que Leff (2006) chama de racionalidade ambiental, a qual seria construída mediante a articulação de quatro níveis de racionalidade: racionalidade teórica; racionalidade técnica ou instrumental; racionalidade cultural; racionalidade material ou substantiva. Esta última se articula com a problemática social do desenvolvimento. Pensa-se aqui nos processos ligados à produção e ao consumo, que por sua vez se ligam à racionalidade econômica e à lógica do mercado. O giro proposto por Leff remete ao direito dos povos à autogestão dos recursos ambientais, à preservação das bases ecológicas que permitam o desenvolvimento sustentável. Nessas condições de autogestão, destaca-se a importância da produção de tecnologias adequadas e culturalmente apropriadas pelos atores diretamente envolvidos nos processos sociais. Além disso, postula-se a melhora da qualidade de vida, o que significa a eliminação da pobreza extrema, a melhoria da qualidade do ambiente e o incentivo às práticas produtivas.

O movimento não considera a construção de Belo Monte uma realidade concretizada. Destaca as ações na justiça solicitando embargo da obra considerando as irregularidades no projeto, dentre as quais a de que os impactos socioambientais não estão suficientemente esclarecidos, o que seria causado por falhas no processo de licenciamento ambiental. A estratégia utilizada, então, a partir do início das obras da hidrelétrica, é a de desqualificar o processo, enfatizando as questões trabalhistas, tais como greves, paralisações, prisões de operários, insegurança, entre outras. Como exemplo disso, percebem-se os sliders na página inicial do site, cuja tônica é a exposição de imagens chocantes. As notícias veiculadas passaram a ter enfoque predominante nas denúncias sobre as situações envolvendo os trabalhadores ali envolvidos, sem descuidar, entretanto, que as preocupações com o aspecto ambiental se mantenham ainda evidentes. 
Enfatiza ainda as consequências negativas já perceptíveis a partir do início das obras, como a notícia não assinada "casos de prostituição aumentam em Altamira”, publicada em 29/4/2012. Nessa reportagem cita a Agência Brasil para legitimar/referendar a veracidade da informação, o que é feito também em outras notícias veiculadas no site. A estratégia pauta-se no argumento de que quanto mais publicidade for dada às questões negativas, mais possibilidades há de influenciar a opinião pública e reverter as questões, nesse ponto, aquelas relacionadas aos direitos humanos e à situação dos trabalhadores ali alocados.

Finalmente, percebe-se a influência de uma expertise nas discussões apresentadas pelo movimento. Os conceitos e categorias explicitados em várias manifestações demonstram uma coerência nas propostas apresentadas. Algumas vezes determinados nomes de pessoas ligadas às instituições de pesquisas e Universidades são citados verbalmente, demonstrando uma ligação/aproximação destas com o movimento. Outras vezes, podemos perceber nas falas dos atores as influências de determinadas matrizes teóricas. Isso demonstra uma coerência das pesquisas e seus desdobramentos na construção de novos referenciais para se pensar a Amazônia. O próprio Painel de Especialistas, aqui referido, apesar da falta de eco nos setores responsáveis pelas decisões estatais demonstra essa aproximação com a problemática ambiental percebida na Amazônia e a necessidade da comunidade científica acompanhar os processos em curso.

\section{Considerações finais}

A construção da hidrelétrica de Belo Monte é compreendida no contexto do projeto desenvolvimentista para o país, no qual a Amazônia é vista como plataforma de recursos a serem explorados em favor do grande capital. Nessa perspectiva, esse projeto de geração de energia deverá beneficiar a outros que exploram recursos naturais da Amazônia. O Movimento Xingu Vivo Para Sempre procura estabelecer relações entre Belo Monte e outros projetos já desenvolvidos, como a hidrelétrica de Tucuruí, destacando suas implicações negativas ao ambiente e às populações, a fim de projetar as consequências danosas às coletividades locais, fortalecendo os argumentos contrários ao empreendimento.

Belo Monte caracteriza-se pelo caráter desenvolvimentista, mas em 
uma perspectiva diferente das tentativas anteriores, as quais foram pautadas no viés geopolítico e econômico. Não é uma perspectiva de integração, mas de exploração dos recursos naturais. Perspectiva de fortalecer os grandes empreendimentos, os quais não tem se traduzido em benefícios para as coletividades locais - os deslocamentos compulsórios, notadamente daqueles moradores do curso do rio, por exemplo, desconsiderando os modos de vida pautados na relação com a natureza, com os movimentos de tempo, não marcados pelo relógio/calendário, mas regulados pela natureza, na sazonalidade, na pesca, são provas de que o desenvolvimento não se destina aos amazônidas.

Os deslocamentos compulsórios causados por empreendimentos anteriores, tal como Tucuruí, não se traduziram em melhoria de vida, mas em desagregação social e suas consequências, como o aumento da pobreza, migração para as periferias das cidades, agravando os problemas sociais urbanos.

Os pilares desenvolvimento/energia estão interligados e dão a tônica do processo. Esta última pode ser vista como suporte/alicerce para a concretização da primeira. Apresentam-se como pilares fundamentais e, por isso mesmo, fortes o suficiente para demandar grandes obras e executá-las. Mas nas franjas dos pilares (ou no interior destes) estão os atores sociais como fatores de resistência, desgastando as estruturas por meio de ações locais, mas com alcance mundial, beneficiado pela utilização das novas mídias disponíveis em larga escala, resistindo à visão hegemônica do desenvolvimento, corroendo-o. Fazem uso de recursos originários desses pilares: as novas tecnologias de informação e comunicação, as quais não existem sem energia e são geridas e geradas dentro da perspectiva do desenvolvimento, da modernização e da industrialização. Essas promovem a criação de várias mídias que utilizadas pelos movimentos de resistência acabam de certa forma fragilizando o sistema. Por outro lado, há polarização dos debates e, dentre estes, há contraargumentação da necessidade de geração de energia para a manutenção dessas mídias, as quais são utilizadas pelo movimento, em acusações de posições acríticas: ao mesmo tempo em que utiliza as benesses do desenvolvimento, critica-o. 


\section{Referências}

BERMANN, Célio. O projeto da Usina Hidrelétrica Belo Monte: a autocracia energética como paradigma. Novos Cadernos Naea, v. 15, n. ${ }^{\circ}$ 1, p. 5-23, jun., 2012.

BRASIL. Constituição. Brasília: Senado, 1988.

CARTA Xingu Vivo Para Sempre. Disponível em: http://www.socioambiental. org/nsa/detalhe?id=2687.

CASTELLS, Manuel. A Galáxia da Internet: reflexões sobre a Internet, os negócios e a sociedade. Rio de Janeiro: Jorge Zahar Editor, 2003.

- A sociedade em rede. São Paulo: Paz e Terra, 2008 (A Era da Informação: economia, sociedade e cultura, vol. 1).

. O poder da identidade. São Paulo: Paz e Terra, 2006 (A Era da Informação: economia, sociedade e cultura, vol. 2).

COELHO, M. C. N; MIRANDA, E; WANDERLEY, L. J.; GARCIA, T. C. Questão energética na Amazônia: disputa em torno de um novo padrão de desenvolvimento econômico e social. Novos Cadernos Naea, v. 13, n. ${ }^{\circ}$ 2, p. 83102, dez., 2010.

DEFENDENDO OS RIOS DA AMAZÔNIA. Parte 1. Disponível em: http://www.youtube.com/watch?v=4k0X1bHjf3E\&feature=plcp. Acesso em: 22/2/2012.

DEFENDENDO OS RIOS DA AMAZÔNIA. Parte 2. Disponível em: http://www.youtube.com/watch?v=JcCpFBro-Lc\&feature=plcp. Acesso em: 22/2/2012.

ESCOBAR, A. El lugar de la naturaliza y la naturaliza del lugar: globalización o posdesarrollo. In: VIOLA, A. Antropologia del Desarrollo. Teorías y estúdios etnográficos em America Latina. Barcelona: Paidós, 2000.

- América Latina en una encrucijada: ¿modernizaciones alternativas, postliberalismo o posdesarrollo? In: BRÉTON, V. (Ed.). Saturno devora a sus hijos: miradas críticas sobre el desarrollo y sus promesas. Barcelona: Icaria Editorial, 2010. 
KOHLHEPP, Gerd. Estratégias de desenvolvimento regional na Amazônia brasileira. Finisterra, XVI, 31, Lisboa, 1981, p. 63-94.

LEFF, Enrique. Racionalidade Ambiental: a reapropriação social da natureza. Rio de Janeiro: Civilização Brasileira, 2006.

LOUREIRO, Violeta R. Amarônia: Estado, homem, natureza. Belém: Cejup, 2004.

MAgAlHÃES, S.; HERNANDEZ, F. (Orgs.). Painel de Especialistas. Análise Crítica do Estudo de Impacto Ambiental do Aproveitamento Hidrelétrico de Belo Monte. 2009. Disponível em: http://www.socioambiental.org/banco imagens/pdfs/ Belo_Monte_Painel_especialistas EIA.pdf. Acesso em: 4/4/2012.

MCCORMICK, John. Rumo ao Paraíso: a história do movimento ambientalista. Rio de Janeiro: Relume-Dumará, 1992.

MORAL HERNÁNDEZ, F. D.; MAGALHÃES, Sonia Barbosa. Ciência, cientistas e democracia desfigurada: o caso Belo Monte. Novos Cadernos Naea, vol. 14, n. $1,2011$.

MOVIMENTO XINGU VIVO PARA SEMPRE. Carta à presidente Dilma Rousseff. Disponível em: http://www.xinguvivo.org.br/wp-content/ uploads/2010/10/carta Dilma-versao final 08fev11.pdf).

RAVENA, N.; TEIXEIRA, E. F. Usina de Belo Monte: quando o desenvolvimento viola direitos. Ponto de Vista, n. . 10, outubro, 2010.

VIOLA, E. O movimento ambientalista no Brasil (1971-1991): da denúncia e conscientização pública para a institucionalização e o desenvolvimento sustentável. In: GOLDENBERG, M. (Org.). Ecologia, ciência e politica. Rio de Janeiro: Revan, 1992.

ZHOURI, A. Belo Monte: crise do sistema ambiental e da democracia. Disponível em: http://www.youtube.com/watch?v=npoLn9pzJ5E. Acesso em: 15/3/2012.

O Ativismo Transnacional pela Amazônia: entre a ecologia política e o ambientalismo de resultados. Horizontes Antropológicos, ano 12, n. ${ }^{\circ}$ 25, p. 139-169. jan./jun., 2006. 


\section{Postagens utilizadas}

"Belo Monte não vai sair porque é uma grande farsa". Disponível em: www. xinguvivo.org.br/2011/04/10/“belo-monte-nao-vai-sair-porque-e-umagrande-farsa”. Acesso em: 24/7/2012.

Além do mito das barragens como "energia limpa", por Brent Millikan. Disponível em: xinguvivo.org.br/2012/06/06/alem-do-mito-das-barragenscomo-energia-limpa-por-brent-millikan/. Acesso em: 24/7/2012.

Ato em Belém reúne manifestantes em defesa do Xingu Vivo. Disponível em: www.xinguvivo.org.br/2012/06/28/ato-em-belem-reune-manifestantes-emdefesa-do-xingu-vivo/. Acesso em: 24/7/2012.

Audiência pública no TRF1: circo sem graça. Disponível em: www.xinguvivo. org.br/2011/07/09/audiencia-publica-no-trf1-circo-sem-graca/. Acesso em: 24/7/2012.

Belo Monte de Equívocos. Disponível em: www.xinguvivo.org.br/2010/11/17/ belo-monte-de-equivocos/. Acesso em 24/7/2012.

Belo Monte e a palavra do presidente. Disponível em: www.xinguvivo.org. br/2010/10/11/belo-monte-e-a-palavra-do-presidente/. Acesso em:24/7/2012.

Belo Monte pode levar caos a Altamira, diz procurador. Disponível em: www. xinguvivo.org.br/2011/09/21/belo-monte-pode-levar-caos-a-altamira-dizprocurador/. Acesso em: 24/7/2012.

Bianca Jagger faz apelo contra hidrelétricas na A mazônia. Disponível em: www. xinguvivo.org.br/2012/03/24/bianca-jagger-faz-apelo-contra-hidreletricasna-amazonia/. Acesso em: 24/7/2012.

BNDES tem discurso verde e prática cinza. Entrevista especial com João Roberto Lopes Pinto. Disponível em: xinguvivo.org.br/.../bndes-temdiscurso-verde-e-pratica-cinza-entrevista-especial-com-joao-robert... Acesso em: 24/7/2012.

Construir para destruir. Disponível em: www.xinguvivo.org.br/2010/10/11/ construir-para-destruir/. Acesso em: 24/7/2012.

Declaração final do Xingu + 23. Disponível em: www.xinguvivo.org. 
br/2012/06/17/declaracao-final-do-xingu-23/. Acesso em: 24/7/2012.

Dom Erwin Kräutler: "Há gente do PT que parece fanático religioso" - parte 4. Disponível em: xinguvivo.org.br/2012/.../dom-erwin-krautler-ha-gentedo-pt-que-parece-fanatico-religioso-parte-4/. Acesso em: 24/7/2012.

Dom Erwin Kräutler: "Hoje vivemos em uma ditadura civil" - parte 5. Disponível em: www.xinguvivo.org.br/2012/06/06/dom-erwin-krautler-hojevivemos-em-uma-ditadura-civil-parte-5/. Acesso em: 24/7/2012.

Dom Erwin Kräutler: "Não há palavras para o que senti diante do caixão da Dorothy" - Final. Disponível em: xinguvivo.org.br/.../dom-erwin-krautlernao-ha-palavras-para-o-que-senti-diante-do-caixao-da-dor... Acesso em: 24/7/2012.

Eliane Brum: A pequenez do Brasil Grande. Disponível em: www.xinguvivo. org.br/2011/10/17/eliane-brum-a-pequenez-do-brasil-grande/ 1/. Acesso em: $24 / 7 / 2012$.

Falta de debate sobre plano decenal de energia é alvo de críticas em audiência pública. Disponível em: xinguvivo.org.br/.../falta-de-debate-sobre-planodecenal-de-energia-e-alvo-de-criticas-em-audienci... Acesso em: 24/7/2012.

Governo cria plano de desenvolvimento sustentável para Xingu. Disponível em: www.xinguvivo.org.br/2010/10/24/governo-cria-plano-de-desenvolvimentosustentavel-para-xingu/. Acesso em: 24/7/2012.

Governo Dilma: crescimento vs direitos humanos? Disponível em: www. xinguvivo.org.br/2011/01/04/governo-dilma-crescimento-vs-direitoshumanos/. Acesso em: 24/7/2012.

Hidrelétricas em construção são socialmente injustas, diz Jorge Viana. Disponível em: xinguvivo.org.br/2012/05/06/hidreletricas-em-construcaosao-socialmente-injustas-diz-jorge-viana/. Acesso em: 24/7/2012.

Indígenas contra Belo Monte, a favor de outro desenvolvimento. Disponível em: $\quad$ www.xinguvivo.org.br/2011/02/10/indigenas-contra-belo-monte-afavor-de-outro-desenvolvimento/ Acesso em: 24/7/2012.

Índios da Amazônia alertam para ameaça da construção de Belo Monte. Disponível em: xinguvivo.org.br/2011/03/27/indios-da-amazonia-alertam- 
para-ameaca-da-construcao-de-belo-monte/. Acesso em: 24/7/2012.

Leonardo Sakamoto - Belo Monte é a pedra no discurso de Dilma. Disponível em: www.xinguvivo.org.br/2011/09/21/leonardo-sakamoto-belo-monte-e-apedra-no-discurso-de-dilma/ Acesso em: 24/7/2012.

Meio Ambiente e Direitos Humanos. Disponível em: www.xinguvivo.org. br/2011/03/25/meio-ambiente-e-direitos-humanos/ Acesso em: 24/7/2012.

Movimentos sociais em Altamira descartam participação no Comitê Gestor do PDRS Xingu. Disponível em: xinguvivo.org.br/.../movimentos-sociaisde-altamira-descartam-participacao-no-comite-gestor-do-p... Acesso em: 24/7/2012.

Um procurador contra Belo Monte. Disponível em: www.xinguvivo.org. br/2011/09/06/eliane-brum-um-procurador-contra-belo-monte/ Acesso em: 24/7/2012. 